\title{
O pedagogo e os problemas de aprendizagem na alfabetização: contribuições da pesquisa de intervenção
}

\section{The pedagogue and the learning problems at literacy: contributions of intervention research}

\author{
Noemi Mendes Alves Lemes, Maria Irene Miranda, Maria Isabel de Araújo \\ Missão Sal da Terra, Univ. Fed. de Uberlândia, Prefeitura Municipal de Uberlândia
}

\begin{abstract}
Resumo
Este trabalho é resultado de uma parceria entre Universidade Federal de Uberlândia e Secretaria Municipal de Educação de Uberlândia, Brasil, para realização de pesquisa-ação em escola pública com estudantes com dificuldades na alfabetização. O objetivo foi favorecer a melhoria no processo do ensino e aprendizagem por meio de projetos de intervenção psicopedagógica, favorecendo a aprendizagem dos estudantes pesquisados. A coleta de dados utilizou entrevistas, observações, avaliações psicopedagógicas, documentos e materiais pedagógicos. A pesquisa revelou que a psicopedagogia contribuiu com o trabalho de educadores e com a revisão da prática pedagógica oferecida na escola.

Palavras-Chave: Psicopedagogia; Aprendizagem; Pesquisa de intervenção.
\end{abstract}

\begin{abstract}
This article proposed a partnership between Federal University of Uberlândia and Municipal Secretary of Education of Uberlândia, Brazil, to conduct an actionresearch in public schools with students with literacy difficulties. The objective was to favor the improvement in the teaching and learning process, through projects of psychopedagogical intervention promoting the learning of the researched students. Data collection used interviews, observations, psychopedagogical evaluation, documents and Pedagogical materials. The research revealed that psychopedagogy contributed with the work of educators and with the revision of the pedagogical practice offered in the school.
\end{abstract}

Keywords: Psychopedagogy, Learning, Intervention research.

O presente texto consiste no relato de pesquisa realizada no período de fevereiro de 2012 a fevereiro de 2014, em uma escola pública municipal da cidade de Uberlândia, Estado de Minas Gerais, Brasil.

$\mathrm{Na}$ intenção de desenvolver uma pesquisa de intervenção, em 2011, o GEPPE/UFU (Grupo de Estudo e Pesquisa sobre a Psicopedagogia Escolar da Universidade Federal de Uberlândia) realizou os primeiros contatos com a escola para definição dos problemas de pesquisa.

Nas primeiras visitas foi possível identificar a demanda da instituição relacionada ao processo de alfabetização de crianças nos anos iniciais do ensino fundamental, especificamente no $1^{\circ}$ e $2^{\circ}$ anos. Identificou-se também um grande interesse e predisposição da escola em participar da pesquisa, condição fundamental para o trabalho coletivo próprio da pesquisa de intervenção.

Por meio de reuniões entre os educadores da escola e participantes do GEPPE foram constituídas as questõesproblemas de pesquisas:

- De que forma os pedagogos podem contribuir para diminuir a evasão e repetência do aluno considerado problema de aprendizagem nas escolas públicas de ensino fundamental?

- De que maneira o viés psicopedagógico pode contribuir com a ação do pedagogo frente aos problemas de aprendizagem?

- Como articular projetos de ação pautados na pesquisa e voltados para as necessidades dos alunos e professores mediante o processo de alfabetização?

- Como realizar investigações, levantar hipóteses e questões sobre as dificuldades do aluno e sobre o processo pedagógico, propondo uma avaliação crítica e o surgimento de novos procedimentos?

Com base na problematização e no referencial teórico da psicopedagogia foram elencados os objetivos do trabalho:

- Favorecer a melhoria da qualidade do ensino oferecido na escola, por meio de projetos de intervenção psicopedagógica que visam promover a aprendizagem e o sucesso escolar dos alunos com problemas de aprendizagem.

- Possibilitar a realização e socialização de estudos, pesquisas e ações referentes aos subsídios da Psicopedagogia Escolar para o Pedagogo, diante dos problemas de aprendizagem no processo de alfabetização.

- Desenvolver Estudos de Caso Psicopedagógico no âmbito escola campo e da Faculdade de Educação da Universidade Federal de Uberlândia.

- $\quad$ Possibilitar a interlocução entre a universidade e demais instituições de ensino, por meio da pesquisa de intervenção.

- Oferecer curso de formação continuada para professores e pedagogos que atuam junto aos alunos com problemas de aprendizagem na alfabetização, sendo esse o objeto da investigação. Mediante a 
compreensao e definição dos problemas e os objetivos foi iniciado o processo de construção dos dados.

\section{Método}

Por se tratar de uma pesquisa de intervenção, a problemática que orientou a investigação foi definida no campo de estudo, no contato com a realidade e com os participantes. A pesquisa de intervenção foi a opção metodológica que ao ver das pesquisadoras atende a complexidade do fenômeno da não aprendizagem, pois se apresenta por uma natureza multideterminada . Assim essa modalidade de pesquisa deve analisar as evidências, interpretando o que está subjacente e que provoca determinados impedimentos. Yin (2005)

\section{Os instrumentos}

Para realização do diagnóstico psicopedagógico foram definidos os seguintes instrumentos: entrevista com o professor, entrevista com os pais ou responsáveis (anamnese), entrevista com o aluno, EOCA (Entrevista Operativa Centrada na Aprendizagem), técnica projetiva do Par Educativo, jogos, atividades pedagógicas de leitura e escrita e observação.

EOCA trata-se de uma entrevista com o sujeito sobre a sua aprendizagem escolar, solicitando que desenvolva algumas atividades aprendidas na escola, no decorrer das quais o mediador estabelece um diálogo e observa os argumentos, assim como os elementos utilizados para desenvolver a ação. São disponibilizados materiais diversos como papel, lápis, borracha, canetas, material para colorir, tesoura, cola, papéis coloridos para pintura e/ou recorte. $\mathrm{O}$ mediador solicita ao sujeito que utilize o material disponível para demonstrar algo que aprendeu, ou seja, qualquer atividade que lhe foi ensinada e que ele aprendeu e pode demonstrar. Não há produção certa ou errada, o processo é mais revelador do que o produto.

O importante é a reação do sujeito enquanto produz a atividade, o que ele revela? Demonstra ansiedade? Tem iniciativa? Pede ajuda enquanto produz? Desiste diante das dificuldades? Utiliza a borracha constantemente? As respostas a essas questões ajudam a compreender como o sujeito se relaciona com o conhecimento, qual sua postura diante do aprender (MIRANDA, 2011).

O Par Educativo consiste em um recurso gráfico de diagnóstico psicopedagógico, por meio do qual solicitase ao sujeito que desenhe uma pessoa que ensina e outra que aprende. Na sequência, propõe-se que produza uma história, oral ou escrita, sobre a representação gráfica.

Por meio dessa técnica psicopedagógica, é possível investigar as relações de ensinantes e aprendentes na escola ou não; os papeis desempenhados na escola, concepções de aprendizagem, dentre outras (WEISS, 2004).

\section{Os participantes da pesquisa e o proceso de intervenção}

Participaram da pesquisa de intervenção os alunos indicados pelas professoras e pedagoga da escola campo da pesquisa por apresentarem dificuldades em relação a aprendizagem da leitura e da escrita. No total foram 18 alunos (16 meninos e 2 meninas), do $1^{\circ}$ e $2^{\circ}$ anos, na faixa etária entre 8 e 12 anos de idade; 6 professoras, na faixa etária entre 28 e 54 anos, todas com graduação em pedagogia, sendo 4 com pós-graduação lato sensu; uma pedagoga com 34 anos e pós graduada em educação especial. Estes sujeitos foram identificados no trabalho por categoria e número, preservando assim sua identidade. Ex. Alunos (A1, A2, A3...); Professores (P1, P2, P3...); Pedagoga (PE)

Definidos os sujeitos da pesquisa de intervenção e após o contato com a instituição de ensino no que tange ao esclarecimento da ação e conhecimento dos sujeitos e pesquisadores, procedeu-se o diagnóstico e a intervenção psicopedagógica.

Nas palavras de Vinh-Bang (1990) a intervenção "consiste em criar situações tais que o aluno é chamado a agir mentalmente, de uma maneira que seja estruturante, integrando suas ações num sistema de coordenação e de composição operatórias".

As atividades de intervenção psicopedagógica, pautadas no resultado do diagnóstico, requerem mediação no processo de desenvolvimento e aprendizagem junto a um sujeito que está apresentando um problema e busca resolvê-lo. Visa a desaparição do sintoma e de seus efeitos perversos, almejando favorecer o sucesso escolar e eliminar qualquer possibilidade de fracasso. Como um fator facilitador da aprendizagem, pretende ressaltar as capacidades do sujeito, criando condições favoráveis ao desenvolvimento de suas potencialidades e eliminando obstáculos e dificuldades postas á aquisição do conhecimento, enfim prepara para o aprender a aprender. A intervenção favorece a relação entre o sujeito e o conhecimento.

No presente estudo a intervenção contemplou ações junto aos alunos, seus professores e pais em consonância com os pressupostos da psicopedagogia, que acredita haver modificação nas situações de aprendizagem quando se criam espaços de interlocução para que de forma sistêmica falem a mesma linguagem e assumam responsabilidades na busca de alternativas para solucionar o problema. Não se trata de uma tarefa fácil, pois a tendência é apontar um culpado e não assumir as responsabilidades.

Junto aos alunos as ações de intervenção priorizaram a leitura e a escrita por meio de jogos e atividades lúdicas, diferentes portadores de textos de gêneros diversificados, que se constituíram em ponto de partida para aprendizagem. Todos requeriam esforço de compreensão, pensamento autônomo, iniciativa, capacidade de análise, trabalho coletivo, clima de cooperação e interação. Se no diagnóstico, o trabalho com jogos busca conhecer os conceitos e estruturas que o sujeito dispõe, na intervenção “(...) não objetiva ensinar conceitos ou noções, mas, sim, favorecer os processos de equilibração, em direção à tomada de consciência necessária à construção de qualquer conhecimento" (Miranda, 2008).

O trabalho compreendia momentos individuais e em grupo, respeitando sempre o nível de compreensão do aluno, mas buscando atuar na zona de desenvolvimento proximal, favorecendo, assim, a constituição e o 
desenvolvimento de conceitos, conforme postulado por Vygotsky (1993)

O processo de intervenção e mediação ocorreu também com os professores em um curso de extensão de 40 horas, num trabalho contínuo e cooperativo, uma vez que não existiam verdades absolutas. É sabido que articular projetos de pesquisa de intervenção no interior das escolas não é tarefa simples. As resistências e indisposições para o "fazer diferente" são comuns entre os profesores. O conteúdo do curso para a mediação junto aos docentes consistiu das produções escritas dos estudantes nas quais foram analisados os ditados, as produções de frases e textos (com e sem imagem) e outras atividades de escrita, buscando respaldo no referencial teórico da psicopedagogia, pautado principalmente no interacionismo. Os caminhos e possibilidades foram se constituindo no cotidiano escolar, tendo como objetivo criar situações favoráveis ao avanço conceitual dos alunos em relação a leitura e a escrita.

O referencial teórico estava articulado às demandas de sua atuação, portanto a teoria fazia sentido e não tinha um fim em si mesma. Nessa vertente Ferreiro afirma que:

Os processos de capacitação mais rápidos, profundos e bem sucedidos parecem ser aqueles em que alguém acompanha o professor em serviço. Esse alguém pode ser qualquer pessoa envolvida nas questões (inclusive outro professor), com a condição de que consiga transformar-se em um interlocutor. Ver o que aconteceu em uma hora de aula sob outro ponto de vista, discutir sobre o que se disse ou o que não se disse, sobre o que se fez ou o que não se fez, pôr em discussão o que se pretende e os meios utilizados, refletir sobre os pressupostos implícitos, compartilhar dúvidas e certezas, tudo isso ajuda mais o professor a pensar do que várias horas de aula convencional. (Ferrero, 1993, p.49)

Junto aos pais foram realizadas reuniões trimestrais ressaltando a importância da mediação da família para aprendizagem, assim como as possibilidades de mediar o processo por meio de diálogos e orientações.

Após 18 meses de intervenção era o momento de avaliar as ações desenvolvidas a luz dos objetivos estabelecidos para o estudo.

Pesquisadores e sujeitos constataram que existe uma relação mútua entre diagnóstico e intervenção: o diagnóstico é investigativo e interventivo, e a intervenção é também diagnóstica. Por meio do diagnóstico ocorre uma interferência na vida do sujeito, em sua dinâmica familiar, trazendo indagações e provocando reflexões. Todo esse movimento caracteriza uma intervenção no caso, tanto que alguns sujeitos apresentaram certa evolução durante o diagnóstico, antes da intervenção propriamente, eles se animaram ao ver que alguém se voltou para o seu caso, que existia uma tentativa de ajudá-lo a superar suas supostas dificuldades. É nesse sentido que o diagnóstico é também interventivo. Entretanto, nem todas as perguntas foram respondidas durante o diagnóstico, algumas respostas foram obtidas durante a intervenção, conhecendo melhor os sujeitos em todos os seus aspectos. Em outras palavras, "Não há fronteiras formais entre diagnóstico e tratamento. A separação normalmente feita é apenas operacional (...)" (Weiss, 1991).

Uma vez realizado o diagnóstico (aplicação e análise), o grupo dispunha de elementos para o planejamento da intervenção psicopedagógica. As crianças atendidas se mostravam inseguras, não estabeleciam vínculos com o que não conheciam, e aprender significa construir um vínculo com o desconhecido para desvendá-lo e torná-lo conhecido. A aprendizagem requer aspectos que as crianças ainda não dispunham: confiança, principalmente em si mesma, coragem de se relacionar com o mundo, pessoas e objetos, aprender a agir e reagir. Toda a sua forma de interação com o meio precisava ser revista (família, escola, amigos), portanto a intervenção não podia envolver apenas as crianças, mas todos a sua volta. Sobre esse caso o grupo discutiu algumas questões básicas: Por que as crianças possuem esse perfil? Traços de personalidade? Modelos de educação que vivenciou? Mecanismo de defesa? As explicações estavam em processo de vir a ser, à medida que o grupo avançava nos estudos.

\section{A análise dos dados}

Toda a proposta de intervenção se pautou na análise de dados. Um dos momentos mais complexos e que exigiu o confronto da teoria com a empiria para desvendar o que estava implícito no dado. Nesse sentido o papel da teoria foi fundamental, pois estruturou e organizou o material observado.

Ao analisar as respostas obtidas nas atividades do diagnóstico a grande questão não foi verificar se estava certo ou errado, mas sim investigar como o sujeito estava procedendo no momento de aprender, como interagia com o objeto de conhecimento. O mediador não impunha respostas ou tinha qualquer expectativa quanto ao resultado, o que lhe cabia era estimular e desafiar, esperando que o sujeito explicitasse suas ideias.

Fernández (1991) alerta para a necessidade de desvendar a modalidade de aprendizagem do aprendente, segundo a autora "a modalidade de aprender é como a matriz, um molde, um esquema de operar que vamos utilizando nas diferentes situações de aprendizagem" (Fernández, 1991).

No decorrer da análise o grupo buscou estabelecer relações entre os fatos e nenhum dado foi analisado de forma estanque, pois "qualquer que seja a técnica empregada no diagnóstico, o resultado deve ser encarado numa perspectiva dinâmica, de forma a orientar a busca de soluções e não como um fim em si mesmo" (Bossa, 2000).

Ao fazer as conexões, as causas do problema começam a ser desvendadas. Busca-se a opinião dos teóricos a respeito. A compreensão se ampliou à medida que foram estabelecidas relações com outros dados e com os referenciais teóricos. Nessa fase do trabalho foi preciso ter muita cautela para evitar análises equivocadas ou enviesadas, o que poderia comprometer as possibilidades de intervenção. As dúvidas foram 
comuns, pois são inerentes ao processo, já que o caminho não estava definido, e nem o percurso a ser seguido era linear, mas estava sujeito a conflitos, contradições e modificações. Isto acontece porque o diagnóstico é uma atividade dinâmica, está em constante movimento e é passível de revisões e reconsiderações.

A análise de dados exigiu enorme atenção e se configurou em uma etapa extremamente importante no trabalho da pesquisa de intervenção, isso porque oportunizou conhecer os resultados obtidos e também as possibilidades de respostas ao problema da pesquisa.

Dos 18 estudantes que iniciaram o projeto, 16 chegaram até o final apresentando uma evolução conceitual significativa, à medida que já compreendiam como o sistema de escrita funciona. No entanto, alguns $(60 \%)$ estavam em processo de construção das convenções ortográficas, enquanto outros (40\%) estavam alfabéticos ortográficos. Não foram considerados os dados iniciais dos 2 estudantes desistentes.

Os dados acima confirmam aos pressupostos psicopedagógicos de Ferreiro e Teberosky (1999), quando afirmam que primeiramente as crianças constroem a compreensão acerca do sistema de funcionamento da escrita para posteriormente dominar suas convenções ortográficas.

Fica evidente no estudo que a perspectiva psicopedagógica, pode contribuir de forma significativa com o trabalho de pedagogos e professores alfabetizadores, respaldando o desenvolvimento de projetos de pesquisa de intervenção condizentes às necessidades de alunos alfabetizandos. Para tanto pedagogos e professores alfabetizadores precisam recorrer ao estudo investigativo das causas das dificuldades de aprendizagem, retirando o foco somente do aluno, como historicamente ocorre.

Se o sujeito se constitui nas relações, o aluno precisa ser considerado na interface dos diversos fatores que compõem as suas interações. Trata-se de dispensar um olhar mais sistêmico ao aprendente.

Nesse contexto, participar da pesquisa implicou em realizar uma auto-avaliação, revendo procedimentos já arraigados e acomodados na prática do dia a dia e buscando novas alternativas. As reações dos docentes variaram entre o envolvimento e o desânimo, tanto que dos 6 participantes 2 desistiram no decorrer do processo. Para aqueles que permaneceram ficar até o final também foi um desafio.

"confesso que participar do projeto, fazer os estudos, não foi fácil, pensei em desistir, pois já tenho o trabalho da outra escola, mas fui ficando e agora acho que valeu a pena, aprendi muito, olho para os textos dos alunos com outros olhos" (P6).

"Gostei muito do curso, das discussões dos textos, ler tudo aquilo foi puxado, mas vai me ajudar a planejar melhor minhas aulas daqui pra frente" (P3).
"O pessoal da universidade ajudou muito agente, sala de primeiro ano não é moleza não, agente precisa mesmo de ajuda, orientação, o curso ajudou também, agente trocou experiência" (P1)

A partir dos depoimentos de alguns professores pode-se inferir que a pesquisa, à medida que desenvolveu a intervenção psicopedagógica visando promover a aprendizagem e o sucesso escolar dos estudantes em processo de alfabetização, contribuiu para a melhoria da qualidade do ensino oferecido na escola, assim para diminuir a evasão e a repetência.

\section{Os resultados obtidos}

Foi possível constatar por meio da pesquisa que todos podem aprender desde que o ensino seja condizente as necessidades, o que remete aos saberes e práticas docentes. Logo não é possível trabalhar com o estudante sem envolver o docente. Outra constatação importante da pesquisa foi a repercussão positiva na autoestima dos estudantes. A pesquisa ocasionou, também, o enriquecimento no processo de formação de todos os envolvidos, isso porque possibilitou estudos, diálogos constantes entre a equipe de educadores abrangida e pais das crianças referente a intervenção e ainda, a possibilidade de apresentação do trabalho de estudo e pesquisa.

Finalizar uma pesquisa de intervenção que envolve atendimentos e vínculos, principalmente de crianças, requer procedimentos no sentido de prepará-las para o encerramento das atividades. Assim o cuidado, as precauções e o acolhimento ao iniciar o trabalho, foi levado a efeito ao finalizá-lo. Os estudantes foram avisados com antecedência que as atividades do projeto seriam encerradas no final do ano letivo de 2013, juntamente com as aulas regulares, e que, isso se devia ao fato de que eles (os estudantes) aprenderam muito sobre a leitura e a escrita e não mais precisavam dos atendimentos.

O mesmo cuidado foi dispensado aos pais, em reunião de devolutiva onde foram informados sobre o encerramento do projeto na escola, ressaltando novamente a evolução de seus filhos.

$\mathrm{Na}$ reunião com os docentes, pedagoga e diretora foram retomados os objetivos do projeto e a problematização da pesquisa, esclarecendo sobre o encerramento do trabalho. Nesse momento ficou evidente que a psicopedagogia contribuiu de forma significativa com a atuação do pedagogo e dos docentes, favorecendo a proposição de ações para superar os problemas de aprendizagem no processo de alfabetização. Também, proporcionou uma aproximação entre a escola e a universidade, articulando o conhecimento teórico e prático. E assim, a escola teve a oportunidade participar ativamente da pesquisa e do curso de extensão para embasar sua práxis de sala de aula.

Por fim, se a cultura do fracasso e da exclusão ainda se faz presente no contexto escolar, a pesquisa revelou que é possível superar a estrutura educacional seletiva e excludente e estabelecer um paradigma de formação 
humana integral, tendo como referência as potencialidades e possibilidades de aprender.

\section{Referências}

Bossa, N. A. (2000). A Psicopedagogia no Brasil. 2a ed. Porto Alegre: Artes Médicas.

Fernández, A. (1991). A inteligência aprisionada: abordagens psicopedagógicas clinicas da criança e sua família. Porto Alegre: Artes Médicas.

Ferreiro, E. (1993). Com todas as letras. $2^{\mathrm{a}}$ ed. São Paulo: Cortez.

Ferreiro, E. \& Teberosky, A. (1999). Psicogênese da língua escrita. Trad. Beatriz Cardoso. Petrópolis, Vozes.

Miranda, M. I. (2008). Problema de Aprendizagem na Alfabetização e Intervenção Escolar. São Paulo: Cortez Editora.

Vinh-bang. (1990). A intervenção psicopedagógica. In: Archives de Psychologie. $N^{o}$ 58, 123-135. Paris.

Vygotsky, L. S. (1993). A Formação Social da Mente. São Paulo: Martins Fontes.

Yin, R.K. (2005) Estudo de Caso: planejamento e métodos. 3ed. Porto Alegre: Book-man.

Weiss, M. L. L. (1991). Reflexões sobre diagnóstico psicopedagógico. In: Scoz, B. J. L. et al. (org.) Psicopedagogia: contextualização, formação $e$ atualização profissional. (pp. 94-139). Porto Alegre: Artes Médicas. 